Article

\title{
Seeing the Wood for the Trees: Factors Limiting Woodland Management and Sustainable Local Wood Product Use in the South East of England
}

\author{
Caroline Greenslade ${ }^{1, *}$, Richard Murphy ${ }^{1}{ }^{(\mathbb{D}}$, Stephen Morse ${ }^{1}$ and Geoffrey H. Griffiths ${ }^{2}$ \\ 1 Centre for Environment and Sustainability, University of Surrey, Guildford GU2 7XH, UK; \\ rj.murphy@surrey.ac.uk (R.M.); s.morse@surrey.ac.uk (S.M.) \\ 2 Department of Geography and Environmental Science, The University of Reading, Whiteknights, \\ P.O. Box 227, Reading RG6 6AB, UK; g.h.griffiths@reading.ac.uk \\ * Correspondence: c.greenslade@surrey.ac.uk; Tel.: +44-7710-297920
}

Received: 4 November 2020; Accepted: 20 November 2020; Published: 2 December 2020

\begin{abstract}
The South East of England has an abundance of woodland, which offers a potential sustainable timber and fuel resource in parallel with being a much-loved part of rural life and rich ecological wildlife habitat. An ever-increasing quantity of mature broadleaved trees is available for harvest forms, with appropriate management and a sustainable yield potential, set against the backdrop of only $10 \%$ of UK timber demand currently supplied from UK-grown resource. There has been little systematic research into the factors that limit the sector and initiatives to address the challenge have not had a significant impact on the amount of woodland under management. Through semi-structured interviews across the wood supply chain, this research provides an integrated analysis of the factors limiting woodland management in the South East of England. The findings indicate the sector is complex, multifaceted, slow to respond to change and driven by a strong set of human, economic, environmental, and structural motivations away from use of local wood product. A novel insight from the research was that although there was a positive affinity for forestry and a strong culture of woodland management across the spectrum of stakeholders, there was little evidence of effective collaboration or sector integration. These factors have been summarised in a 'rich picture' providing a visual and intuitive way of engaging with stakeholders. This research fills a significant gap in understanding the dynamics of forestry in the South East of England and provides new underpinning evidence for policy makers to design interventions aimed at delivering better sustainable utilisation of woodland resources in parallel with offering support to rural communities and economies.
\end{abstract}

Keywords: woodland management; forestry; wood products; sustainability; rich picture; policy

\section{Introduction}

Woodland is $13 \%$ of land cover in the UK, but only 10\% in England [1]. Despite being just a third of the coverage of most other European countries and with slow progress towards the government's target of 12\% (in England) by 2060 [2], woodland is still a significant element of the landscape, particularly in the South East of England.

Woodlands have multiple potential uses including as a leisure environment, a material and energy resource, and provision of other ecosystem services such as flood protection, carbon sinks, and 'green lungs'. According to the Natural Capital Committee, every 250,000 hectares of woodland adds $£ 500$ million of societal benefits from ecosystem services [3], although most of these services cover the woodland as an ecological growing resource rather than when harvesting and extraction is taken into consideration. 
Within England, about $60 \%$ of woodlands are hardwood [1], while most of the 'mass market' for forest products focuses on the quicker growing and easier to handle softwoods. Despite the great range of uses and demand for woodland products, there is relatively little use of extracted hardwood resource in the UK. Annually the UK consumes around 500,000 $\mathrm{m}^{3}$ of hardwood for use in a range of products (biomass, sawn hardwood for boards, joinery products, etc.), yet only $10 \%$ is currently sourced from within the UK [4]. This is not due to a lack of available resource or the sustainability of extracting it from the woodland. There is 6 million $\mathrm{m}^{3}$ of hardwood available for extraction between 2022 and 2061 [1], from which, using a conservative estimate of only $10 \%$ for quality saw logs and a conversion rate for processing of two thirds, would result in $400,000 \mathrm{~m}^{3}$ of end product sawn timber hardwood that could be produced every year from English woodlands for the next 40 years without reducing the overall standing stock [5]. Within the South East of England, the situation is most acute, with $25 \%$ of the national total of 'overdue' wood biomass (trees past the age that they have been defined as available for felling, either by management plans or post the maximum Mean Annual Increment (MAI) point where growth rate slows down), yet the area has the least commensurate scale of wood product utilisation (sawmills, processing plants, and final consumer utilisation) of any region in the UK [6]. The potential opportunity to utilise more of this wood resource is also restricted by local rural supply chains and wood harvesting and working skills becoming increasingly dormant [7]. The active management of a woodland for a variety of purposes can be considered to increase the overall environmental sustainability of the land [8]. For example, removal of trees for processing into woodfuel can benefit diversity of wildlife through creating open areas within woodland and make the woodland structure more resilient through multi-age woodland [9]. In addition, removal of trees for timber purposes, as long as it is undertaken in a sustainable way, can create gaps in woodland cover that encourage greater biodiversity [10].

Over the previous two decades, there have been a range of initiatives instigated by the government, the Forestry Commission and non-governmental organisations (NGOs) to attempt to increase the percentage of wood resource reaching supply chains. These have largely focused around financial grants and programmes to increase information and awareness amongst owners, but validation of outcomes is sparse and comparison between interventions very limited [11]. Furthermore, most interventions are targeted on a primary measure of outcome, for example in encouraging the planting of new trees, but do not consider the multivariate nature of woodland management where a positive outcome for the system as a whole may not be delivered through the same outcome in different patches of woodland or with different owners [12,13]. Although the introduction of the Renewable Heat Incentive (RHI) has had a positive impact, it and other programmes have not significantly altered the outlook for the sector at large [2].

Whilst some of the global literature has relevance to the UK, the particularly acute situation within the South East of England has not been directly studied. The high density of the population, dispersed tree cover, congested transport network and varied geographic terrain make the counties of the South East of England a particularly challenging domain for a functioning forest sector. Blockers and solutions that are experienced in this region are therefore highly relevant to understanding the UK and more global challenges associated with woodland management. This research seeks to establish the reasons for the under-utilisation of broadleaved wood product resource in the South East of England.

Previous research has focused on the decision making of those involved in the forest supply chain, particularly around the decision to actively manage a particular area of woodland. Traditionally, research has focused on an owner as an agent of rational economy theory (e.g., [14-16]), where the decision not to harvest wood is seen as a purely economic response to a lack of markets or a poor economic return for investment [17]. This analysis appears compelling for the South East of England, given that woodland areas are small, separated, and on hard-to-access land with an increased financial burden of extraction and a lack of local markets for non-traditional wood products. However, an economic focus as the sole driver for decision making has been found to be an inadequate rationalisation, with research repeatedly finding that economic incentives alone do not 
motivate increased management, and that owners and managers report increasing financial returns are not sufficient to change behaviour [18,19]. Other research has focused on the personal characteristics of woodland owners and managers and their motivations for management decisions (e.g., [20-22]). Studies have found that an owner's motivations for forest ownership are considered (in a self-reported measure) to be the most important indicators of woodland activity, with financial incentivisation only working when linked to these broader motivations [23].

When behaviour change is considered, work has been done on behavioural impacts and interventions and their incorporation into economic and attitudinal models [24], including how behavioural 'nudges' can impact on forest management activities [25]. Whilst case studies have been published where this approach has been undertaken (e.g., [26]), there is generally a lack of systematic research undertaken relating to behavioural impacts within parallel sectors applied to UK forestry. This extends to environmental motivation; for example, whilst climate change and disease have been identified as the primary concerns of woodland owners in the UK in 2017 [27], there is little academic research that explores how these motivations impact on owner decision making [28]. Finally, recent research has focused on the social practice underpinning management, with increasing attention to human culture and how it impacts on landscape. This approach highlights landscape as a dynamic entity not solely viewed as a resource base-landscape can be seen to co-evolve with the human environment and as a function of the development of a collective psychology. Therefore, any consideration of woodland decision making should also be considered alongside a wider perspective on the individuals and culture involved within it $[29,30]$. This requires examination of how individuals form part of a social network and how the attitudes and values of this network impact on individual and collective decision making [31,32]. This offers potential opportunities for targeting of interventions that address not just single owners but their entire social environment.

Therefore, the current evidence base indicates a range of potential challenges facing woodland management in the South East of England, although most research to date has not taken a regional sector-wide approach to capture the breadth of factors impacting output. This research aims to fill that gap by exploring the reasons for low levels of woodland management in South East England (Hampshire, Surrey, and West Sussex) leading to under-utilisation of broadleaved wood product resource.

\section{Materials and Methods}

The study uses a structured interview approach with twenty-one individuals involved in the forestry sector in the South East of England to acquire qualitative data with some complementary quantitative responses. The interview data have been collected and analysed using a grounded theory approach to allow the key factors to emerge. Grounded theory is an approach to qualitative data analysis that supports the development of theories through the analysis of captured data [33]. The underlying structure of the concept and its inter-relationships are allowed to emerge from the data through the analysis process, encouraging review of a dataset without pre-conceived ideas about a coding framework [34]. These factors have then been captured in a graphic representation as a 'rich picture' to facilitate stakeholder discussion and engage wider communities with the challenges [35].

Participants were identified through snowball sampling designed to capture a breadth of roles across the supply chain from woodland owners to contractors, agents, and those people involved in establishing policy and strategy for the sector (Table 1) and with a range of sizes of business/operation (Table 2). An initial set of ten respondents was identified by engagement with the South East Forestry and Woodland Advisory Committee, who provided what they considered to be a range of individuals with a balanced perspective from different aspects of the sector. Each of these then identified additional respondents, and so on. Data collection ceased at twenty-one participants as similar findings were being obtained and no additional factors were being retrieved. The split between owners, agents, contractors, and policy workers was not fully balanced as in several cases woodland owners passed the interview request to their agents, which resulted in a larger number of agent interviews than owner interviews. This was particularly the case for 'medium' scale owners, which resulted in 
an imbalance between owners/agents and size of woodland. Those involved in policy and research were predominantly focused towards medium and large woodlands, as this is where the weight of policy effort is focused. The final participant list was reviewed and validated by the Forestry Commission South East regional office and the South East Forest and Woodland Advisory Committee as being representative of the woodland sector. All subjects gave their informed consent for inclusion before they participated in the study. The study was conducted in accordance with the Declaration of Helsinki, and the protocol was approved by the Ethics Committee of the University of Surrey (project ID: 160708-160702-22137270).

Table 1. Study participants by size and type of business.

\begin{tabular}{clcccc}
\hline & & \multicolumn{3}{c}{ Size of Business } \\
\hline \multirow{3}{*}{$\begin{array}{c}\text { Type of } \\
\text { business }\end{array}$} & Small & Medium & Large & TOTAL \\
& Agent (or resident forester) & 3 & 0 & 1 & 4 \\
& Contractor (feller, chipper, reseller) & 1 & 2 & 4 & 8 \\
& Policy/Research & 0 & 3 & 1 & 5 \\
& TOTAL & $\mathbf{6}$ & $\mathbf{8}$ & $\mathbf{7}$ & $\mathbf{2 1}$ \\
\hline
\end{tabular}

Table 2. Definition of scale/remit of woodland businesses, as defined in [11].

\begin{tabular}{ll}
\hline Classification & Definition \\
\hline SMALL & $\begin{array}{l}\text { Reselling less than } 1000 \text { tonnes of wood a year; less than five contracts; } \\
\text { processing less than } 1000 \text { tonnes a year; woodland (ownership or } \\
\text { management) of less than 15 hectares }\end{array}$ \\
\hline MEDIUM & $\begin{array}{l}\text { Reselling between 1000-5000 tonnes of wood a year; between 5-15 } \\
\text { contracts; processing between } 1000 \text { and 10,000 tonnes a year; woodland } \\
\text { (ownership or management) of between 15 and 50 hectares }\end{array}$ \\
\hline \multirow{2}{*}{ LARGE } & $\begin{array}{l}\text { Reselling over } 5000 \text { tonnes of wood a year; over 15 contracts; processing } \\
\text { more than 10,000 tonnes a year; woodland (ownership or management) } \\
\text { of over 50 hectares }\end{array}$ \\
\hline
\end{tabular}

All interviews were conducted by the same interviewer, face-to-face, in the place of work or home of participants, and each took between 45 and $90 \mathrm{~min}$. The interviews followed a semi-structured approach, with questions chosen to address the aim of the study and based on previous research as described in the literature review. The key topic areas were their business, the dynamics of the industry, and their perspectives on the challenges facing them and the sector as a whole. A summary of interview questions is given in Table 3.

A grounded theory approach to data collection and analysis was undertaken. The interviews were audio recorded and transcribed and emergent content analysis was undertaken to determine the key factors that participants identified as having an impact on either their business and/or wider sector performance. Each interview transcript was coded manually by topics as identified by the interviewee, with a particular focus on the responses to questions in sections 4 (barriers to developing business), 8 (motivations for management of woodland), and 9 (sector wide blockers). The coding framework emerged through transcript analysis, and each transcript was subsequently re-coded against the completed framework of topics once all interviews were completed and analysed. All data was stored and used in accordance with relevant data security legislation and good practice. 
Table 3. Semi-structured interview format.

\begin{tabular}{|c|c|c|c|}
\hline Section & Question Topic & Description & Qualitative/Quantitative \\
\hline 1 & Introduction & $\begin{array}{l}\text { Overview of the research topic } \\
\text { Overview of the approach to } \\
\text { the interview } \\
\text { Summary of consent, signing of } \\
\text { consent form }\end{array}$ & Discussion \\
\hline 2 & Business information & $\begin{array}{l}\text { Business information-size, } \\
\text { scale, type } \\
\text { Motivations for personal career } \\
\text { choice }\end{array}$ & $\begin{array}{l}\text { Ordinal category choice } \\
\text { Qualitative comment }\end{array}$ \\
\hline 3 & Woodland activities & $\begin{array}{l}\text { Main activities undertaken in } \\
\text { woodland } \\
\text { Time taken to complete activities }\end{array}$ & $\begin{array}{l}\text { Ordinal category choice } \\
\text { Qualitative comment }\end{array}$ \\
\hline 4 & Barriers & $\begin{array}{l}\text { Rating of barriers to business } \\
\text { development }\end{array}$ & $\begin{array}{c}\text { Quantitative } \\
\text { (with supporting } \\
\text { qualitative comment) }\end{array}$ \\
\hline 5 & Relationship to others & $\begin{array}{l}\text { Levels of cooperation and } \\
\text { collaboration with suppliers, } \\
\text { customers and other peer } \\
\text { businesses } \\
\text { Barriers to cooperation }\end{array}$ & Qualitative comment \\
\hline 6 & $\begin{array}{l}\text { Perceived change } \\
\text { (historical and future) }\end{array}$ & $\begin{array}{l}\text { Change over the last five years } \\
\text { Predicted change over the next } \\
\text { five years }\end{array}$ & Qualitative comment \\
\hline 7 & Costs & $\begin{array}{l}\text { Main cost to business } \\
\text { Prices for product } \\
\text { Change in price (backwards and } \\
\text { forwards) }\end{array}$ & Qualitative comment \\
\hline 8 & $\begin{array}{l}\text { Motivations for } \\
\text { management }\end{array}$ & $\begin{array}{l}\text { Reasons why people are } \\
\text { choosing to manage/not manage } \\
\text { woodland }\end{array}$ & Qualitative comment \\
\hline 9 & Sector wide blockers & $\begin{array}{l}\text { Blockers to development of } \\
\text { the sector }\end{array}$ & Qualitative comment \\
\hline 10 & Conclusion & $\begin{array}{l}\text { Summary of key points } \\
\text { Any other issues not raised }\end{array}$ & Qualitative comment \\
\hline
\end{tabular}

The resultant set of factors was quantitatively analysed by the frequency of reporting between participants, resulting in a rating of either 'high', 'medium', or 'low' by frequency of identification. High frequency factors were identified by $>70 \%$ (14 or more participants), medium frequency factors by between $40-70 \%$ (between eight and 12 participants), and low frequency factors by $20-40 \%$ (between four and eight participants). Any factors identified by less than $20 \%$ (four participants) were not considered to be commonly identified issues. Factors were also subjectively grouped by four dimensions: human, financial, structural, or environmental, dependent on the topic area.

The factors identified through the content analysis were used to generate a graphic representation (rich picture) of the main components, issues, and connections between actors in the woodland management and utilisation system. The rich picture was produced by the researchers in collaboration with an artist and was presented to three stakeholder groups for validation and identification of areas for further investigation: the Forestry and Woodland Advisory Committee, a cross sector grouping established to advise the Forestry Commission in the South East; a grouping of members of the Royal Forestry Society; and staff members and woodland advisors from the Forestry Commission. Some amendments were made following these reviews to clarify ambiguities and strengthen 
the communication message. The factors and rich picture were reviewed and analysed to draw conclusions about the sector as a whole and the blockers impacting on its growth and development.

\section{Results}

Based on content analysis of the interview transcripts, a set of 38 factors were identified by participants as impacting on woodland management and under-utilisation of broadleaved wood product resource. Ten factors were considered to be 'high' frequency (Table 4), thirteen 'medium' frequency (Table 5), and fifteen 'low' frequency (Table 6). A description of the high and medium frequency factors is introduced below, organised by their primary dimension (human, financial, structural, or environmental).

Table 4. High frequency factors impacting woodland management and under-utilisation of woodland resource.

\section{Human factors}

- Ownership motivations not aligned to active management.

\section{Financial factors}

- Exchange rate results in cheaper imported product reducing home-grown market.

- Marginal financial return from activity_high cost of management activity, handling friction, poor sale return.

- Long payback period for early years thinning and management activity.

\footnotetext{
Structural factors

- Poor woodland infrastructure, including access to and within woodlands.

- Dispersed nature of woodlands.

- Small pockets of private ownership.

- Lack of availability of information appropriately targeted to owners.

- Lack of availability of skilled resource to support owners, including Forestry Commission woodland officers.
}

\section{Environmental factors}

- Impact of pests and diseases-positive financial return requires very active pest and disease management.

\subsection{Human Factors}

The single high frequency human factor identified was the relationship between ownership motivation and active management. For example, in cases where the reason for woodland ownership was not for resource extraction or economic optimisation, there was a decreased likelihood of management activity being undertaken. In cases where management of woodland would actively conflict with ownership motivation (for example where ownership was primarily for ecological outcomes in conflict to tree felling), interviewees indicated extremely high resistance to changing management patterns. Farmers were perceived to value woodland differently to agricultural land, seeing the only useful purpose of areas of trees being to hide disused farm equipment. This is seen to impact on levels of farm woodland management and openness to new initiatives focusing on both new plantings and management of existing trees. Other medium frequency factors identified centre on information and awareness, with a reported lack of understanding and knowledge from owners and the general public about the potential ecological, silvicultural, and economic value of woodland management. In addition, it was felt that conflicting information resources confuse owners as to what 'doing the right thing' would look like in their woods. 
Table 5. Medium frequency factors impacting woodland management and under-utilisation of woodland resource.

\section{Human factors}

- Lack of understanding about the ecological value of undertaking woodland management and negative public perception of tree felling.

- Actual and perceived land quality factors with woodland valued less positively than other agricultural land.

- Low level of risk appetite-owners not willing to risk new management approaches.

- Low level of cooperation amongst owners/agents/contractors with little sharing of knowledge and innovation.

- Lack of knowledge-owners want to 'do the right thing' but no knowledge or agreement what that would be.

\section{Financial factors}

- $\quad$ Poorly targeted and inappropriately structured (e.g., requiring a high cost contribution) financial incentives.

\section{Structural factors}

- $\quad$ Lack of a regional wood storage hub infrastructure for timber and woodfuel resource.

- Woodland businesses are localised, often small, and with low incentive for growth.

- Little vertical integration in the supply chain.

- High levels of perceived bureaucracy in managing woodland/engaging with incentives.

\section{Environmental factors}

- Long timescales associated with tree growth impacting both financial returns and resistance to change.

- History of woodland use and management-no actively managed forestry sector for many decades.

- Woodland on marginal land resulting in increased infrastructure and access challenges.

\subsection{Financial Factors}

From a financial perspective, three high frequency factors were identified. The level of exchange rate disadvantage. which results in an imported product being cheaper than a home-grown alternative at the point of sale, was particularly important for low margin products used in construction and fencing. The marginal level of financial return from most woodland management activity was also a factor-most interviewees accepted that financial return did not need to be positive to justify activity, but could not be consistently significantly in deficit. This is exacerbated by a long payback period for early years thinning and management activity. The only variation in this was for larger estates, where it was accepted that other estate activities would fund the management of woodland, given a longer-term perspective and a strong value of custodianship of the land for future generations. Medium frequency factors were government financial policy incentives, which were perceived to be poorly targeted, not sufficient in quantity, not offered in a way that was usable for most owners (for example offering payment post activity rather than prior to activity being undertaken), requiring significant time to apply for and receive, and not offering support for the most important structural challenges such as infrastructure development. The resource intensive nature of woodland management operations was also cited as a factor, with a high friction cost in terms of labour and machinery costs and time for handling and movement of wood product. 
Table 6. Low frequency factors impacting woodland management and under-utilisation of woodland resource.

\section{Human factors}

- Lack of workforce skill and competence to address challenge of small, dispersed, and inaccessible woodland.

- An aging workforce, with the sector not seen as attractive or financially rewarding for young arboriculturalists.

- Historical emotional perspective-post the 1987 'great storm', many owners ceased woodland management, either because of the large cost of clear up or the emotional impact of losing large amounts of tree cover.

\footnotetext{
Financial factors

- High fuel costs impacting cost of transport.

- $\quad$ Low oil price impacting interest in woodfuel as a fuel source.

- Financial pressures on large estates means less opportunity for activities with a poor return (e.g., forestry).

- $\quad$ Reducing levels of the government funded 'Renewable Heat Incentive', which originally incentivised woodfuel, creating uncertainty.

- $\quad$ Cost of insurance and indemnity for public access.

- Lack of a consistent woodland ownership tax incentive.
}

\section{Structural factors}

- Machinery not adapted for use in English woodlands.

- Woodland conversion is perceived to limit landowner flexibility.

- Historical policy emphasising planting of native woodland species over softwoods has resulted in product with less of an existing processing capability and market.

- Public access issues of woodland.

\section{Environmental factors}

- Concern about depletion of micronutrients by extraction of product from woodland.

- Changing species mix due to climate change and pests and diseases.

- Changing practices of management including continuous cover forestry.

\subsection{Structural Factors}

Structural high frequency factors centred on the pattern of woodland ownership in the South East, with dispersed woodlands, unmanaged woodland dominating marginal land, and with small pockets of private ownership. This geographic challenge is further compounded by the level of woodland infrastructure in the South East, including access to and within woodlands. A lack of appropriately skilled resources to support owner decisions and advise on activity was identified, supported by a lack of availability of information targeted to owners and high levels of perceived bureaucracy required to administer the management of woodland. Most of the rationales for these factors focusing on skilled resource cited access to, and the skill levels of, the Forestry Commission 'Woodland Officers', whose role has significantly changed over the past decade from offering direct, free, and impartial support to owners to being reduced to a much lower level due to funding constraints. A further structural factor was the lack of a wood storage hub for consolidation of woodfuel and timber resources, which may offer a solution to the problem caused by small pockets of private ownership and resultant small quantities of wood product brought to market.

\subsection{Environmental Factors}

The single high frequency environmental factor was the impact of pests and diseases on owner motivation and financial return, a very active pest and disease management policy being required 
to facilitate long term financial return. Medium impact factors include the historical context of woodland use and management in the area and the timescale associated with tree growth. Full outcome timeframes from growing and managing woodland are longer than an individual's lifetime, making realisation of both financial and non-financial benefits difficult. In addition, there is a recognised challenge for owners and woodland users to perceive landscape management on longer-than-human timescales, resulting in a widespread resistance to perceived landscape change.

A range of lower frequency factors were also identified, as summarised in Table 6. These are not discussed further, as the lower frequency indicates the factors are not so universally agreed upon.

\subsection{Rich Picture}

The set of factors identified, alongside raw interview quotes, was reviewed in a workshop with a rich picture artist. From this session, an initial concept for a graphic articulation of the dynamics of the sector was generated, aiming to incorporate as many of the high and medium frequency factors as possible and using participant quotes to offer authentic comment. Initial sketches of the rich picture were aired with three different groups of participants over a period of a couple of months, and elements were adjusted to accurately represent the summary of factors. Since production of the final version, which can be seen in Figure 1, the rich picture has been used in a range of different settings to support discussions with the government department Defra on the future of environmental policy and as an introduction to further research by the authors focusing on specific areas within the sector. 


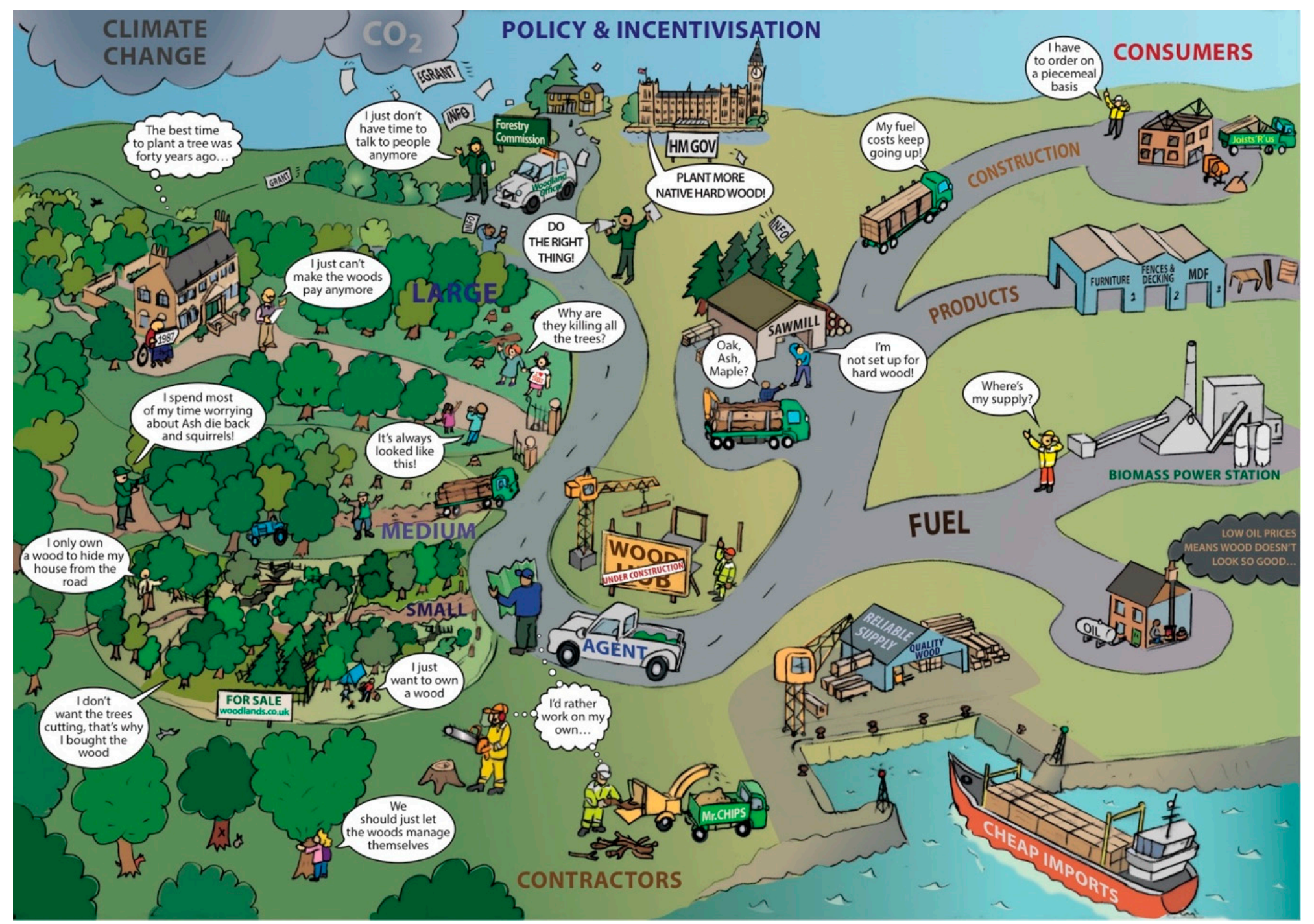

Figure 1. Rich picture representation of the factors impacting the wood produce sector in the South East of England. 


\section{Discussion}

Based on the analysis of the factors identified through the interviews and stakeholder socialisation of the rich picture visual summary, a set of conclusions can be drawn about the social, economic, and structural blockers limiting woodland management and the use of woodland wood product in the South East of England.

\subsection{A Highly Inter-Connected and Complex Sector}

The wood product and forestry sector in the South East of England is complex, multifaceted, slow to change, and driven by a set of strong motivations-human, economic, environmental, and structural-away from woodland management and use of local wood resource. The identification of thirty-eight factors currently perceived to impact on the sector indicates the breadth of challenge that must be addressed in order to exert change. The sector has been dominated by historical networks and has adapted very little to modern demand, resulting in a vulnerability to cheaper, mass-produced, and economically more efficient product from overseas. Furthermore, the combination of human, economic, environmental, and structural factors all co-existing and co-impacting means that interventions that are primarily designed to impact just one or two of these factors are highly unlikely to break the complex network of impacts.

\subsection{Human and Individual Aspects}

The complexity of the sector is exacerbated by the deep cultural and psychological perspectives that individuals who engage with the wood product sector have in relation to woodland. Formed as part of a nature-culture nexus [36] combining both historical and traditional beliefs and modern values and understanding, as well as an individual's interaction with the environment [37], the sense of people and place in landscape is deeply rooted in us as individuals and as communities. These motivational human factors have been found to be generally the most difficult and slow to change and are the least likely to be impacted by economic incentives $[19,20]$, which is limiting the impact of a number of the policy initiatives in the area.

\subsection{Economic and Business Aspects}

Across all dimensions, a view of the woodland management sector in the South East emerged that found businesses to be highly localised, often small, and with a low incentive for growth. There was little vertical integration in the supply chain and little aspiration for any further vertical integration with the overall level of horizontal cooperation between owners, agents, or contractors being surprisingly very low.

The consumer demand signal is present and growing, but weak, and not well supported by an unreliable supply chain with sometimes lower quality and efficiency than alternative sources. Traditional market analysis would indicate that a strengthening demand should have a concomitant impact on supply and should operate to tighten overall efficiency of the network. Qualitative feedback from this research has indicated that there is a consumer demand for local hardwood, but this is often overtaken by a financial and economic imperative for cheaper, often softwood, product, particularly within the highly competitive housing construction business. This is strengthening the import market. The current supply-side network has been found to be perceived to be of lower quality and with higher levels of inefficiency, which result in increased cost and material wastage.

\subsection{Physical Environment and Sector Structural Dimensions}

Structural work is underway on infrastructure elements to support better linking between supply and demand (e.g., wood hubs, supply networks, woodland, and transport infrastructure) but progress is slow and rarely strategically coordinated. The junction between supply and demand was repeatedly identified as the critical point for focus to increase the efficiency of the network. Evidence was offered 
from interview respondents about the structural improvements taking place in these areas, particularly around the development of wood hubs and increases in infrastructure investment in individual woodlands and in road transport networks. These developments are not, however, universal across the region, and there still remain large pockets of isolated woodlands that are difficult to access or manage. Furthermore, the physical infrastructure development has not been matched with parallel social and economic cooperation between elements of the supply chain, either horizontally or vertically. There is little cooperation or collaboration across the sector, and this is particularly true at the junction point of supply and demand, where the 'woodland agent' market is segregated and often working neither as an efficient collaboration nor a productive competition.

\subsection{Policy Incentivisation}

Policy and financial incentivisation have been attempted but have had only marginal impact on a complex system of inter-related factors. Participants offered a perspective that the current set of informational, economic, and structural incentives that are in place through policy levers do not operate in conjunction with each other, do not always address the primary concerns of owners, and have a bureaucratic and administrative overhead that often precludes their utility. Even if a set of policy levers were in place that addressed the high impact factors in economic or structural areas, however, it would be difficult to see how they alone could impact given the multi-dimensional nature and complexity of the problem space. Given the high predominance of human social impacts, it is likely that behavioural approaches need to be incorporated in policy to achieve positive outcomes in addition to purely economic policy instruments, and therefore recent behavioural 'nudge' approaches (e.g., [26]) may be appropriate avenues to explore.

\subsection{Addressing Societal, Cultural, and Individual Behaviours}

The cultural, perceptual, and behavioural shift of woodland owners and contractors may offer the greatest opportunity to encourage increased supply of resources and therefore unlock the supply side challenges. Woodlands are more than an economic or environmental resource; the perspectives offered through this study have found they are predominantly a social and cultural point of historical heritage, an everyday leisure and psychological retreat, and viewed in a multi-dimensional and multi-faceted, often conflicting, perspective by woodland users. This finding, echoing the multidimensionality previously found [24], indicates that personal motivations must be taken into consideration, along with financial incentivisation, when considering intervention. These reasons for ownership and how they may conflict with management objectives requires further investigation in order to fully recognise the complexity of the woodland product chain in the South East of England.

\subsection{Limitations and Constraints on the Study Conclusions}

This study has taken a qualitative approach to understanding the factors impacting on sector efficiency in a regional area. The conclusions therefore are a result of the perspectives from those involved within the sector and have not been broadly externally tested or validated; however, they reflect findings from other research conducted in the sector and provide a useful base for further investigation in other areas with similar characteristics. Every attempt was made to get a breadth of views across the sector, but it is recognized that this is necessarily a view based on a limited sample, particularly for such a widely dispersed and disaggregated industry. Finally, this research has focused exclusively on the South East of England, whereas the policy and economic landscape is country-wide, and so a sector approach should be built within a national context. It would therefore be important to test these findings in other regions to assess the applicability of the conclusions for national policy implications. 


\section{Conclusions}

This research has explored the factors impacting on levels of woodland management in the South East of England and identified a set of 38 factors, captured within a graphic rich picture, that are currently restricting increased management activity across the supply and demand network.

It has resulted in the following conclusions:

(a) The wood product and forestry sector in the South East of England is complex, multifaceted, slow to change, and driven by a set of strong motivations-human, economic, environmental, and structural-away from use of local wood resource.

(b) The consumer demand signal is present and growing, but weak and not well supported by an unreliable supply chain with lower quality and efficiency than alternative sources.

(c) Structural work is underway on infrastructure elements to support better linking between supply and demand, but progress is slow and rarely strategically coordinated.

(d) There is little cooperation or collaboration across the sector, particularly at the junction point of supply and demand, little vertical integration in response to market opportunity, and largely informal information sharing networks which limit the spread of innovation across the sector.

Author Contributions: Conceptualization: C.G., R.M., S.M., and G.H.G.; methodology: C.G., R.M., S.M., and G.H.G.; formal analysis: C.G., R.M., and S.M.; investigation: C.G.; resources: R.M., S.M., and G.H.G.; data curation: C.G.; writing-original draft preparation: C.G.; writing—review and editing: C.G., R.M., S.M., and G.H.G.; supervision: R.M., S.M., and G.H.G., project administration: R.M. and S.M.; funding acquisition: R.M., S.M., and G.H.G. All authors have read and agreed to the published version of the manuscript.

Funding: The first author is supported by a PhD studentship for the first author funded by the Economic and Social Science Research Council (ESRC) South East Doctoral Training Centre.

Acknowledgments: The study is collaborative with the Forestry Commission whose support is gratefully acknowledged, particularly the supervision and guidance of Alison Field and Ian Tubby throughout the research. We also wish to acknowledge the cooperation and engagement of many respondents in the woodland and forestry sector.

Conflicts of Interest: The authors declare no conflict of interest.

\section{References}

1. Forestry Commission. Forestry Facts and Figures 2020. 2020. Available online: https://www.forestresearch. gov.uk/documents/7806/CompleteFS2020.pdf (accessed on 13 October 2020).

2. Independent Panel on Forestry, Forestry in England: Seeing the Wood for the Trees-Department for Farming and Rural Affairs. Available online: https:/www.publications.parliament.uk/pa/cm201617/cmselect/ cmenvfru/619/61902.htm (accessed on 30 November 2020).

3. Natural Capital Committee. The State of Natural Capital: Protecting and Improving Natural Capital for Prosperity and Wellbeing. Third Report to the Economic Affairs Committee. 2015. Available online: https://www.gov.uk/government/uploads/system/uploads/attachment_data/file/516725/ncc-statenatural-capital-third-report.pdf (accessed on 1 April 2017).

4. Grown in Britain. WoodStock-Final Report. 2016. Available online: https://sylva.org.uk/blog/wp-content/ uploads/GiB-WoodStock-WS5-Final-Report-FINAL-Sep-16.pdf (accessed on 5 December 2016).

5. 50-Year Forecast of Hardwood Timber Availability; NFI Statistical Analysis Report; Forestry Commission, Edinburgh: 2014. Available online: www.forestresearch.gov.uk\%2Fdocuments\%2F2752\%2F50_YEAR_ FORECAST_OF_HARDWOOD_AVAILABILITY.pdf\&usg=AOvVaw2cr7q0KZrfCc7fGzcgnjVm (accessed on 13 October 2020).

6. Ditchburn, B. The National Forest Inventory and the Potential of Forest Resource; Forestry Commission: Edinburgh, UK, 2013.

7. Woodland Trust. The State of the UK Forest. 2011. Available online: https://www.woodlandtrust.org.uk/ mediafile/100229275/stake-of-uk-forest-report.pdf (accessed on 22 September 2019).

8. Fares, S.; Mugnozza, G.S.; Corona, P.; Palah, M. Sustainability: Five steps for managing Europe's forests. Nature 2015, 519, 7544. [CrossRef] 
9. Bellamy, C.; Barsoum, N.; Cottrell, J.; Watts, K. Encouraging Biodiversity at Multiple Scales in Support of Resilient Woodlands; Forestry Commission Research Note 33; Forestry Commission: Edinburgh, UK, 2018.

10. Chaudhary, A.; Burivalova, Z.; Koh, L.P.; Hellweg, S. Impact of Forest Management on Species Richness: Global Meta-Analysis and Economic Trade-Offs. Sci. Rep. 2016, 6, 23954. [CrossRef]

11. Eves, C.; Johnson, M.; Smith, S.; Quick, T.; Langley, E.; Jenner, M.; Richardson, W.; Glynn, M.; Anable, J.; Crabtree, B.; et al. Analysis of the Potential Effects of Various Influences and Interventions on Woodland Management and Creation Decisions, Using a Segmentation Model to Categorise Sub-Groups. In Woodland Management Segmentation and Assessment of Interventions; Defra: London, UK, 2015; Volume 3.

12. Lawrence, A.; Ambrose-Oji, B. Beauty, friends, power, money: Navigating the impacts of community woodlands. Geogr. J. 2015, 181, 268-279. [CrossRef]

13. Kumar, P.; Kant, S. Revealed social preferences and joint forest management outcomes. For. Policy Econ. 2016, 72, 37-45. [CrossRef]

14. Alchian, A.A. Uncertainty, evolution, and economic theory. J. Polit. Econ. 1950, 58, 211-221. [CrossRef]

15. Van Den Bergh, J.C.; Ferrer-i-Carbonell, A.; Munda, G. Alternative models of individual behaviour and implications for environmental policy. Ecol. Econ. 2000, 32, 43-61. [CrossRef]

16. Farrell, E.P.; Führer, E.; Ryan, D.; Andersson, F.; Hüttl, R.; Piussi, P. European forest ecosystems: Building the future on the legacy of the past. For. Ecol. Manag. 2000, 132, 5-20. [CrossRef]

17. Adams, P.W.; Hammond, G.P.; McManus, M.C.; Mezzullo, W.G. Barriers to and drivers for UK bioenergy development. Renew. Sustain. Energy Rev. 2011, 15, 1217-1227. [CrossRef]

18. Bohlin, F.; Roos, A. Woodfuel supply as a function of forest owner preferences and management styles. Biomass Bioenergy 2002, 22, 237-249. [CrossRef]

19. Church, A.; Ravenscroft, N.; Rogers, G. Woodland Owners' Attitudes to Public Access Provision in South-East England; Forestry Commission Information Note; Forestry Commission: Edinburgh, UK, 2005.

20. Conway, M.C.; Amacher, G.S.; Sullivan, J.; Wear, D. Decisions nonindustrial forest landowners make: An empirical examination. J. For. Econ. 2003, 9, 181-203. [CrossRef]

21. Novais, A.; Canadas, M.J. Understanding the management logic of private forest owners: A new approach. J. For. Econ. 2010, 12, 173-180. [CrossRef]

22. Ficko, A.; Boncina, A. Probabilistic typology of management decision making in private forest properties. For. Policy Econ. 2013, 27, 34-43. [CrossRef]

23. BenDor, T.; Shoemaker, D.A.; Thill, J.C.; Dorning, M.A.; Meentemeyer, R.K. A mixed-methods analysis of social-ecological feedbacks between urbanization and forest persistence. Ecol. Soc. 2014, 19, 3. [CrossRef]

24. Shogren, J.F. Behavior in forest economics. J. For. Econ. 2007, 12, 233-235. [CrossRef]

25. Moseley, D.; Dandy, N.; Edwards, D.; Valatin, G. Potential for Behavioural Policy 'Nudges' to Encourage Woodland Creation for Climate Change Mitigation. 2014; Forest Research Note. Available online: https://www.forestresearch.gov.uk/research/behavioural-policy-nudges-to-encourage-woodlandcreation-for-climate-change-mitigation/ (accessed on 30 November 2020).

26. Valatin, G.; Moseley, D.; Dandy, N. Insights from behavioural economics for forest economics and environmental policy: Potential nudges to encourage woodland creation for climate change mitigation and adaptation? For. Policy Econ. 2016, 72, 27-36. [CrossRef]

27. British Woodland Survey, BWS 2017 Workshops Phase 2 Results. 2017. Available online: https://www.rfs.org. uk/media/481577/bws2017-report.pdf (accessed on 30 November 2020).

28. Lawrence, A.; Marzano, M. Is the private forest sector adapting to climate change? A study of forest managers in north Wales. Ann. For. Sci. 2014, 71, 291-300. [CrossRef]

29. Dandy, N. Woodland neglect as social practice. Environ. Plan 2016, 48, 1750-1766. [CrossRef]

30. De Almeida, G.M.; Ramos, M.A.; Araújo, E.L.; Baldauf, C.; Albuquerque, U.P. Human perceptions of landscape change: The case of a monodominant forest of Attalea speciosa Mart ex. Spreng (Northeast Brazil). Ambio 2016, 45, 458-467. [CrossRef]

31. Satake, A. The role of economic incentives and social norms in forest resource management. Ecol. Res. 2007, 22, 21-22. [CrossRef]

32. Nybakk, E.; Lunnan, A.; Jenssen, J.I.; Crespell, P. The importance of social networks in the Norwegian firewood industry. Biomass Bioenergy 2013, 57, 48-56. [CrossRef]

33. Glaser, B.G.; Strauss, A.L. The Discovery of Grounded Theory; Aldine: Chicago, IL, USA, 1967. 
34. Strauss, A.; Corbin, J.M. Basics of Qualitative Research: Grounded Theory Procedures and Techniques; Sage Publications, Inc.: London, UK, 1990.

35. Bell, S.; Berg, T.; Morse, S. Rich Pictures: Encouraging Resilient Communities (Earthscan Tools for Community Planning); Routledge: London, UK, 2016.

36. Fish, R.D. Environmental decision making and an ecosystems approach: Some challenges from the perspective of social science. Prog. Phys. Geogr. 2011, 35, 671-680. [CrossRef]

37. King, H.P.; Morris, J.; Graves, A.; Bradbury, R.B.; McGinlay, J.; Bullock, J.M. The 'debt' is in the detail: A synthesis of recent temporal forest carbon analyses on woody biomass for energy. J. Environ. Psychol. 2017, 53, 185-197. [CrossRef]

Publisher's Note: MDPI stays neutral with regard to jurisdictional claims in published maps and institutional affiliations.

(C) 2020 by the authors. Licensee MDPI, Basel, Switzerland. This article is an open access article distributed under the terms and conditions of the Creative Commons Attribution (CC BY) license (http://creativecommons.org/licenses/by/4.0/). 